\title{
Новые подходы к физической реабилитации больных артериальной гипертонией с использованием тренажерных устройств
}

\author{
А. В. Смоленский, А. Б. Мирошников
}

Российский государственный университет физической культуры, спорта, молодежи и туризма, Москва, Россия

\begin{abstract}
Резюме. Дано рекомендації щодо запровадження методик фізичної реабілітації людей з гіпертонічною хворобою немедикаментозними методами. Розроблено методики занять на циклічних та силових тренажерах, що знижують артеріальний тиск, покращують аеробні можливості, ліпідограму, гемостазіограму крові хворих на артеріальну гіпертонію. Ключові слова: гіпертонія, ліпідограма, гемостазіограма, тренажери.
\end{abstract}

Summary. The article provides recommendations for the implementation of techniques of physical rehabilitation of patients with essential hypertension drug-free methods. The methods developed training on the cycling and weight training equipment, lower blood pressure, improve aerobic capacity, lipid profile, blood Gemostaziogramma patients with arterial hypertension.

Key words: hypertension, lipidogram, gemostaziogramma, fitness equipment.

\begin{abstract}
Актуальность. Артериальная гипертония (АГ) является важнейшим фактором риска основных сердечно-сосудистых заболеваний - инфаркта миокарда и мозгового инсульта, главным образом определяющих высокую смертность в России и во всем мире. До 15 млн человек ежегодно страдают от мозгового инсульта, 1/3 которых умирают [2].

Метод силовой тренировки «Super slow» (статодинамический режим работы мышц) был впервые применен Hutchins K. и включал в себя медленную работу мышц в концентрической и эксцентрической фразах 10/10 с [5]. Хорошо себя зарекомендовали комбинации этого метода при физической реабилитации больных АГ: концентрическая/эксцентрическая фразы - 10/5 с $[6,9]$, концентрическая/эксцентрическая фазы $-5 / 5$ с [1].
\end{abstract}

Цель исследования. Разработка комплексной программы немедикаментозного лечения артериальной гипертонии с помощью тренажерных устройств.

Материалы и методы. Физическая реабилитация проводилась в Спортивно-оздоровительном клубе «Кимберли Лэнд» (Москва). Под наблюдением находились 43 пациента в возрасте $47 \pm 5,5$ лет с основным диагнозом «гипертоническая болезнь II стадии», по степени (АГ II-умеренная), по стратификации риска средний [4]. Пациенты были разделены на две группы: I - контрольная ( $\mathrm{n}=20)$ и II - основная $(n=23)$. По основным клиническим признакам: возрасту, полу, САД ДАД вечер - группы статистически не различались. В исследуемые группы не включали больных с дыхательной, почечной и печеночной недостаточностью, мочекаменной болезнью, эндокринными заболеваниями (в том числе с сахарным диабетом), заболеваниями сосудов конечностей и опорно-двигательного аппарата в стадии обострения. Исследование проводилось с соблюдением процедуры информированного согласия. На время эксперимента участники полностью отказались от приема гипотензивных лекарств.

Длительность программы фризической реабилитации составила 180 дней (96 занятий), объем фризической реабилитации - четыре часа в неделю. Два дня в неделю - аэробная работа на велоэргометре, время работы 60 мин, метод интервальный. Два дня в неделю фризическая реабилитация включала: аэробную работу на велоэргометре - 30 мин и силовую работу на тренажерах.

Перед началом исследования всем больным было проведено комплексное обследование в лаборатории фризкультуры и спорта СК «Балашиха». Определяли такие маркеры тела:

1) мышечная скелетная масса (МСМ);

2) процент подкожной жировой ткани (ПЖТ); 
3) площадь поперечного сечения висцеральной жировой ткани (ВЖТ);

4) вентиляционный аэробный (АэП) и анаэробный порог (АнП).

По данным литературных источников, индекс массы тела (ИМТ), ПЖТ и ВЖТ находятся В прямой связи с риском возникновения артериальной гипертензии [3], поэтому данные маркеров состава тела очень важны при тестировании. Анализ состава тела проводили с помощью биоимпедансного анализа на «IN BODY 720» (Корея). Ступенчатый тест выполняли на велоэргометре «MONARK» $839 \mathrm{E}$, нагрузку задавали, начиная с 20 Вт и с прибавлением по 20 Вт каждые две минуты. Газометрию осуществляли с использованием газоанализатора фрирмы «CORTEX» для измерения потребления кислорода и выделения углекислого газа от вдоха к вдоху. Частоту сердечных сокращений (ЧСС) и R-R интервалы фиксировали с помощью монитора сердечного ритма «POLAR» RS800. Тест выполняли с темпом 75 об мин $^{-1}$ до определения вентиляционного АнП. По результатам тестирования определяли аэробный и анаэробный вентиляционные пороги по методике Wasserman [8]. Взятие и обработку анализов крови всех участников эксперимента на липидограмму и кауголограмму осуществляла лаборатория «ИНВИТРО» (Москва). Образцы крови для исследования были собраны с соблюдением процедуры информированного согласия. Оценивались показатели липидограммы: холестерол, триглицериды, ЛПВП, ЛПОНП, ЛПНП, коэфффициент атерогенности и гемостазиограммы: протромбин, антитромбин III, тромбиновое время, фрибриноген, АЧТВ, MHO.

Методику физической реабилитации больных гипертонической болезнью осуществляли в три этапа работы:

- аэробная - тест на велоэргометре - 19 мин ЧСС на АэП + 1 мин ЧСС на АнП, цикл повторяли три раза (по 60 мин);

- смешанная - аэробная, силовая;

- аэробная - тест на велоэргометре - 29 мин ЧСС на АэП + 1 мин ЧСС на АнП, цикл проводили один раз (30 мин).
Группа I - контрольная: Силовая работа (динамический режим работы мышц). Упражнения на силовых тренажерах - три подхода по 15 двигательных действий в каждом: 1) жимы на горизонтальном тренажере; 2) сгибание рук в локтевых суставах; 3) разгибание рук в локтевых суставах; 4) приседание с гантелями на скамейку; 5) разгибание голени в коленном суставе. Заключительная часть: ходьба на тредбане 15 мин (10 мин $-4,5 \mathrm{kм} \cdot 4^{-1}, 5$ мин $\left.-4 \mathrm{KM} \cdot \mathrm{ч}^{-1}\right)$. Общее время работы - 75 мин, отдых между подходами - 60 с, между упражнениями 180 c.

Группа II - основная: Силовая работа (метод «Super Slow»). Упражнения на силовых тренажерах три подхода по 60 с: 1) жимы на горизонтальном тренажере; 2) сгибание рук в локтевых суставах; 3) разгибание рук в локтевых суставах; 4) приседание с гантелями на скамейку; 5) разгибание голени в коленном суставе. Заключительная часть: ходьба на тредбане 15 мин (10 мин $-4,5 \mathrm{kм} \cdot 4^{-1}, 5$ мин -4 км $\left.\cdot 4^{-1}\right)$. Общее время работы - 75 мин, отдых между подходами - 60 с, между упражнениями - 180 с.

Результаты исследования и их обсуждение. В результате фризической реабилитации достоверно в обеих группах улучшился состав тела больных гипертонической болезнью. Произошло снижение ВЖТ и ПЖТ, при небольшом увеличении МСМ (табл. 1). В результате 180 дней фризической реабилитации МСМ в контрольной и основной группах сохранилась и даже немного увеличилась - в среднем на 7,1 и 6,5 \% соответственно. Понижение процента ПЖТ на 9,5 и 7,6 \% говорит о том, что данные методики эфффективно воздействуют на жировую ткань в среднем на 1,4 \% в месяц при сохранении мышечной ткани. По результатам изменения МСМ и ПЖТ, группы I и II статистически не различаются. Висцеральная жировая ткань - существенный предиктор в развитии гипертонической болезни - изменялась на протяжении всего реабилитационного цикла. Понижение составило 9,3 и $17,3 \%$ соответственно, причем в группе II более выражено и статистически значимо.

ТАБЛИЦА 1 - Динамика показателей состава тела у больных артериальной гипертонией

\begin{tabular}{|c|c|c|c|c|c|}
\hline \multirow{2}{*}{ Маркер тела } & \multicolumn{2}{|c|}{ Группа I (M \pm SD) } & \multicolumn{2}{|c|}{ Группа II (M \pm SD) } & \multirow{2}{*}{$t, t_{r p}(\alpha=0,05)$} \\
\hline & до & после & до & после & \\
\hline МСM, кг & $35,2 \pm 1,6$ & $37,7 \pm 4,6$ & $34,0 \pm 5,6$ & $36,2 \pm 3,1$ & $1,83<2,05$ \\
\hline ПжТ, \% & $29,4 \pm 10,3$ & $26,6 \pm 8,7$ & $27,7 \pm 3,8$ & $20,1 \pm 9,0$ & $1,36<2,02$ \\
\hline ВЖТ, $\mathrm{cm}^{2}$ & $140,4 \pm 4,6$ & $127,0 \pm 7,3$ & $144,2 \pm 9,7$ & $119,1 \pm 7,5$ & $5,36>2,02$ \\
\hline
\end{tabular}


ТАБЛИЦА 2 - Динамика показателей потребления $\mathbf{O}_{2}$ (мл·кг ${ }^{-1} \cdot$ мин $^{-1}$ ) у больных артериальной гипертонией

\begin{tabular}{|l|c|c|c|c|c|}
\hline \multirow{2}{*}{ Маркер тела } & \multicolumn{2}{|c|}{ Группа I (M \pm SD) } & \multicolumn{2}{c|}{ Группа II (M \pm SD) } & \multirow{2}{*}{$\mathbf{t}, \mathbf{t}_{\text {гр }}(\alpha=\mathbf{0 , 0 5})$} \\
\cline { 2 - 6 } & до & после & до & после & \\
\hline АэП & $10,85 \pm 3,1$ & $13,57 \pm 4,6$ & $8,42 \pm 7,2$ & $15,46 \pm 6,5$ & $8,72>2,02$ \\
\hline АнП & $18,32 \pm 2,9$ & $24,63 \pm 9,1$ & $15,28 \pm 4,5$ & $26,33 \pm 10,4$ & $4,44>2,03$ \\
\hline
\end{tabular}

В результате фризической реабилитации достоверно в основной и контрольной группах улучшились аэробные возможности больных артериальной гипертонией: потребление $\mathrm{O}_{2}$ на АэП и на АнП (табл. 2).

Динамика прироста окислительных способностей мышц на АэП составила в конце реабилитационного цикла 25 и 83,6 \% соответственно. Результаты потребления $\mathrm{O}_{2}$ на АнП были так же выражены и статистически значимы в группе II и составили 34,4 и 72,3 \% соответственно.

Основными предикторами атеросклероза являются показатели липидного профриля пациентов больных артериальной гипертензией. В результате фризической реабилитации в группах I и II произошли изменения фрракций холестерина (табл. 3) - общий холестерол крови понизился на 22,2 и 30,5 \% соответственно. Разница между группами I и II составила 8,3 \%, и она была статистически значима. Снижение триглицеридов крови было 58,6 и 59,6 \% соответственно. Изменение по показателям атерогенных липопротеидов ЛПНП и ЛПОНП можно судить об антиатерогенной направленности созданных нами методик. За время фризической реабилитации уменьшилось содержание ЛПНП в контрольной группе I на 21,5 , а в основной - на $28,3 \%$. Достоверно снизились показатели атерогенной фрракции ЛПОНП, разница между группами составила 16,7 \% и была статистически значимой. Известна роль антиатерогенной фракции холестерина ЛПВП в профилактике атеросклероза, ИБС и других заболеваний сердечно-сосудистой системы. В результате проведенной нами физической реабилитации повысился показатель ЛПВН на 6,6 \% в контрольной группе и на $13,9 \%$ - в основной. Разница между ними составила 7,3 \% и была статистически значимой.

Одним из интегральных показателей, позволяющих оценить риск развития атеросклероза, является коэфффициент атерогенности - самый сильный предиктор смертности от ИБС (на $40 \%$ более информативный, чем отдельные показатели ЛПВП и более чем в два раза максимально информативнее общих показателей холестерина) [7]. В результате применения разработанных нами методик фризического воздействия достоверно понизился коэфффициент атерогенности участников реабилитации: в контрольной группе - на 32,6 \%, в экспериментальной - на $46,7 \%$. Разница между группами составила $14,1 \%$ и была статистически значима.

Достоверно после 180 дней регулярных тренировок улучшился фрактор гемостазиограммы крови у больных гипертонической болезнью (см. табл. 3). В результате фризической реабилитации уменьшилось содержание сложного белка протромбина - одного из важнейших показателей

ТАБЛИЦА 3 - Динамика показателей липидограммы и гемостазиограммы у больных артериальной гипертонией

\begin{tabular}{|c|c|c|c|c|c|}
\hline \multirow{2}{*}{ Показатель } & \multicolumn{2}{|c|}{ Группа I (M \pm SD) } & \multicolumn{2}{|c|}{ Группа II (M \pm SD) } & \multirow{2}{*}{$t, t_{r p}(\alpha=0,05)$} \\
\hline & до & после & до & после & \\
\hline Холестерол, ммоль $\cdot \pi^{-1}$ & $7,72 \pm 0,5$ & $6,01 \pm 0,5$ & $7,91 \pm 0,4$ & $5,50 \pm 0,7$ & $2,80>2,02$ \\
\hline Триглицериды, ммоль • ${ }^{-1}$ & $2,73 \pm 0,4$ & $1,13 \pm 0,4$ & $2,77 \pm 0,5$ & $1,12 \pm 0,5$ & $0,09<2,01$ \\
\hline ЛПВП, ммоль $\cdot л^{-1}$ & $1,37 \pm 0,1$ & $1,46 \pm 0,1$ & $1,44 \pm 0,1$ & $1,64 \pm 0,1$ & $4,93>2,02$ \\
\hline ЛПНП (по Фридвальду), ммоль $\cdot л^{-1}$ & $4,97 \pm 0,3$ & $3,90 \pm 0,6$ & $4,76 \pm 0,5$ & $3,71 \pm 0,8$ & $0,87<2,02$ \\
\hline ЛПОНП, ммоль $\cdot л^{-1}$ & $1,01 \pm 0,1$ & $0,79 \pm 0,1$ & $1,10 \pm 0,2$ & $0,60 \pm 0,3$ & $3,32>2,03$ \\
\hline$K_{A}$ & $4,6 \pm 0,7$ & $3,1 \pm 0,5$ & $4,5 \pm 0,6$ & $2,4 \pm 0,5$ & $4,78>2,02$ \\
\hline Протромбин (по Квику), \% & $140 \pm 8,4$ & $104 \pm 19,1$ & $142 \pm 8,0$ & $101 \pm 23,0$ & $0,40<2,02$ \\
\hline Антитромбин III, \% & $90 \pm 5,9$ & $109 \pm 10,0$ & $87 \pm 4,4$ & $116 \pm 8,2$ & $2,18>2,03$ \\
\hline Тромбиновое время, с & $11,2 \pm 0,8$ & $11,9 \pm 1,2$ & $10,7 \pm 0,6$ & $13,4 \pm 1,2$ & $4,06>2,02$ \\
\hline АЧТВ, c & $26,2 \pm 0,9$ & $31,6 \pm 2,6$ & $25,8 \pm 0,8$ & $33,5 \pm 2,4$ & $2,50>2,03$ \\
\hline Фибриноген, г・ ${ }^{-1}$ & $3,6 \pm 0,5$ & $3,1 \pm 0,5$ & $3,8 \pm 0,5$ & $2,7 \pm 0,4$ & $2,66>2,03$ \\
\hline $\mathrm{MHO}$ & $0,91 \pm 0,1$ & $0,97 \pm 0,1$ & $0,87 \pm 0,1$ & $1,06 \pm 0,1$ & $2,83>2,02$ \\
\hline
\end{tabular}


кауголограммы, характеризующего состояние свертывающей системы крови. Понижение его составило в группе I и II 25,7 и 28,9 \% соответственно, а повышение специфического белка антитромбина III - 21,1 и 33,3 \%. Разница в группах составила $12,2 \%$ и была статистически значима. Достоверно в результате фризической реабилитации произошло удлинение тромбинового времени, это говорит о гипокоагуляции крови больных артериальной гипертонией. Разница в показателях составила $19 \%$ и была статистически значима. В подтверждении гипокоагуляции крови участников реабилитации увеличилось активированное частичное тромбопластиновое время (АЧТВ): в группе I - 20,6, а в группе II - 25,2 \%. Разница в показателях составила 4,6 \% и была статистически значима. Проведение фризической реабилитации позволило снизить показатели фибриногена; разница между группами - 15 \%: в группе | - 13,9, а в группе II - 28,9 \% статистически значима. Проводимая нами фризическая реабилитация достоверно увеличила показатели МНО крови больных артериальной гипертензией: в группе I от начальных значений было 6,6, а в группе II -21,8 \%. Разница между группами составила 15,2 \% и была статистически значима.

В результате фризической реабилитации произошло понижение артериального давления в утренние и вечерние часы в контрольной и основной группах (табл. 4). Достоверно уменьшилось систолическое (САД) и диастолическое (ДАД) артериальное давление в утренние часы. Понижение САД составило в контрольной и основной группах (I и II) 14,1 и 19,4 \% соответственно. Разница между группами 5,3 \% статистически значимая. Понижение ДАД в группе I на $15 \%$ и в группе II - на $22 \%$ было статистически значимо. Разница между группами - 7 $\%$, несмотря на то что в результате физической реабилитации были получены достоверные результаты понижения САД в вечерние часы: 15,2 \% в группе I и 17,3 \% в группе II. Разница между группами 2,1 \% была статистически не достоверна. Понижение ДАД в вечернее время суток было более выраженно и статистически значимо в группе II. Показатели ДАД понизились на 14,6 \% в группе I и в группе II - на 23,1 \%.

\section{Выводы}

1. Теоретически обоснована и разработана комплексная программа фризической реабилитации больных артериальной гипертензией с применением циклических тренажеров и статодинамического режима работы мышц, которая показала ряд преимуществ перед традиционной программой реабилитации.

2. Использование методик фризической реабилитации больных артериальной гипертензией с применением циклических тренажеров и статодинамического режима работы мышц позволило значительно понизить предикторы развития атеросклероза, что подтверждается улучшением фракторов гемостазиограммы и липидного профиля пациентов с артериальной гипертонией.

3. Доказано, что использование методики физической реабилитации больных артериальной гипертензией с применением циклических тренажеров и статодинамического режима работы мышц дает существенный гипотензивный эфрфект по сравнению с традиционными методиками реабилитации. Разница гипотензивного эффректа в утренние часы составила: САД - 5,3, ДАД - 7; в вечернее время: САД - 2,1, ДАД - 8,5 \%.

Практическая значимость работы заключается в том, что на основании проведенного исследования разработана и научно обоснована программа комплексной физической реабилитации больных артериальной гипертензией. Программа доступна и проста в выполнении, для нее необходимы только циклические и силовые тренажеры, что дает методике конкурентные преимущества перед аналогичными программами с использованием гипотензивных средств, физиотерапевтических процедур и массажа. Полученные данные могут быть использованы в спортивно-оздоровительных центрах, фритнесклубах, поликлиниках, санаториях и медицинских учреждениях, работающих с больными гипертонической болезнью.

ТАБЛИЦА 4 - Динамика уровня артериального давления (мм рт. ст.) в утренние и вечерние часы у больных артериальной гипертонией

\begin{tabular}{|c|c|c|c|c|c|}
\hline \multirow{2}{*}{ Показатель } & \multicolumn{2}{|c|}{ Группа I (M \pm SD) } & \multicolumn{2}{|c|}{ Группа II (M \pm SD) } & \multirow{2}{*}{$\mathrm{t}, \mathrm{t}_{\mathrm{rp}}(\alpha=0,05)$} \\
\hline & до & после & до & после & \\
\hline $\mathrm{CAД}_{\text {утро }}$ & $163 \pm 8,6$ & $140 \pm 8,8$ & $165 \pm 6,8$ & $133 \pm 6,9$ & $2,8>2,03$ \\
\hline ДАД $_{\text {утро }}$ & $100 \pm 0,8$ & $85 \pm 3,5$ & $100 \pm 2,4$ & $78 \pm 2,1$ & $8,02>2,04$ \\
\hline САД вечер & $171 \pm 6,7$ & $145 \pm 5,5$ & $173 \pm 5,5$ & $143 \pm 6,4$ & $1,59<2,02$ \\
\hline ДАД вечер & $103 \pm 2,4$ & $88 \pm 3,6$ & $104 \pm 1,9$ & $80 \pm 3,5$ & $6,76>2,02$ \\
\hline
\end{tabular}




\section{Литература}

1. Головунина И. С. Новые подходы к программе фризической реабилитации с использованием силовых тренажеров при гипертонической болезни / И. С. Головунина, С. Н. Попов, Ф. Ю. Мухарлямов // Доктор. Ру. - 2010. № 8. - С. $13-17$.

2. Драпкина О. М. Профилактика инсульта / О. М. Драпкина, Я. И. Ашихмин, В. Т. Ивашкин // Рос. мед. вести. - 2007. - № 4. - С. 60-75.

3. Мартиросов Э. Г. Технологии и методы определения состава тела человека / Э. Г. Мартиросов, Д. В. Николаев, С. Г. Руднев. - М.: Наука, 2006. - С. 50-53.

4. Чазова И. Е. Диагностика и лечение артериальной гипертензии (Рекомендации Российского медицинского общества по артериальной гипертонии и Всероссийского научного общества кардиологов) / И. Е. Чазова, Л. Г. Ратова, С. А. Бойцов / / Систем. гипертензии. - 2010. - № 3. - С. 5.

5. Hutchins K. Super Slow: The Ultimate Exercise Protocol / K. Hutchins// Altamonte Springs, Fla: Super Slow Systems Inc., 1992.

6. McClain A. E. Blood Pressure Response to «SuperSlow» vs Traditional Resistance Exercise/ A. E. McClain, R. M. Lyle FACSM; M. G. Flynn FACSM, D. A. Sedlock FACSM / / Medicine \& Science in Sports \& Exercise. - May 2004. - Vol. 36, issue 5. - P. 204.

7. Prospective Studies Collaboration. Blood cholesterol and vascular mortality by age, sex, and blood pressure: a metaanalysis of individual data from 61 prospective studies with 55,000 vascular deaths / Prospective Studies Collaboration S. Lewington, G. Whitlock, R. Clarke et al. // Lancet. 2008. - Jul 26. - N 372(9635). - P. 292.

8. Wasserman K. Anaerobic threshold and respiratory gas exchange during exercise / K. Wasserman, B. Whipp // J. Appl. Physiol. - 1973. - Vol. 35. - P. 236-243.

9. Wickwire P. J. Acute heart rate, blood pressure, and RPE responses during Super Slow Vs. traditional machine resistance training protocols using small muscle group exercises / P. J. Wickwire, R. J. Mclester, J. M. Green, R. T. Crews // Strength Cond Res. - 2009. - Vol. 23, N 1. - P. 72-79.

\section{References}

1. Golovunina I. S. New approaches to physical rehabilitation program with strength training in hypertension / I. S. Golovunina, S. N. Popov, F. J. Mukharlyamov // Doktor. Ru. - 2010. - N 8. - P. 13-17.

2. Drapkina O. M. Stroke Prevention / O. M. Drapkina, J. I. Ashihmin, V. T. Ivashkin // Rus. med. News. - 2007. N 4. - P. 60-75.

3. Martirosov E. G. Technologies and methods for determining the composition of the human body / E. G. Martirosov, D. V. Nikolaev, S. G. Rudnev. - Moscow: Nauka, 2006. P. 50-53.

4. Chazova I. E. Diagnosis and treatment of arterial hypertension (Russian Medical Society Recommendations on arterial hypertension and the All-Russian Society of Cardiology) / I. E. Chazova, L. G. Ratova, S. A. Bojtsov // System hypertension. $-2010 .-\mathrm{N}$ 3. - C. 5.

5. Hutchins K. Super Slow: The Ultimate Exercise Protocol / K. Hutchins / / Altamonte Springs, Fla: Super Slow Systems Inc. - 1992.

6. McClain A. E. Blood Pressure Response to "SuperSlow" vs Traditional Resistance Exercise / A. E. McClain, R. M. Lyle FACSM; M. G. Flynn FACSM, D. A. Sedlock FACSM // Medicine \& Science in Sports \& Exercise. - May 2004. Vol. 36, issue 5. - P. 204.

7. Prospective Studies Collaboration. Blood cholesterol and vascular mortality by age, sex, and blood pressure: a meta-analysis of individual data from 61 prospective studies with 55,000 vascular deaths / Prospective Studies Collaboration / S. Lewington, G. Whitlock, R. Clarke et al. / / Lancet. 2008. - Jul 26. - N 372 (9635). - P. 292.

8. Wasserman K. Anaerobic threshold and respiratory gas exchange during exercise / K. Wasserman, B. Whipp // J. Appl. Physiol. - 1973. - Vol. 35. - P. 236-243.

9. Wickwire $P$. J. Acute heart rate, blood pressure, and RPE responses during Super Slow Vs. traditional machine resistance training protocols using small muscle group exercises / P. J. Wickwire, R. J. Mclester, J. M.Green, R. T. Crews // Strength Cond Res. - 2009. - Vol. 23, N 1. - P. 72-79. 